\title{
High performance and thermal stress analysis of a segmented annular thermoelectric generator
}

\section{Samson Shittu}

Guiqiang $\mathbf{L i}^{\mathrm{a}, *}$

Guiqiang.Li@hull.ac.uk

\section{Xudong Zhao ${ }^{a, *}$}

Xudong.Zhao@hull.ac.uk

\section{Xiaoli $\mathrm{Ma}^{\mathrm{a}}$}

Yousef Golizadeh Akhlaghi

Emmanuel

aschool of Engineering and Computer Science, University of Hull, HU6 7RX, UK

Institute of Robotics, Autonomous Systems and Sensing, University of Leeds, LS2 9JT, UK

*Corresponding authors.

Abstract

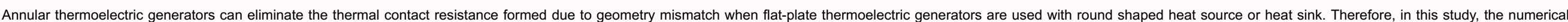

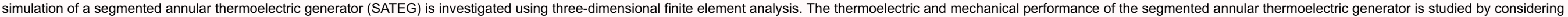

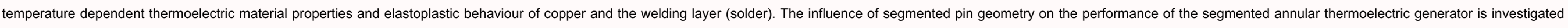

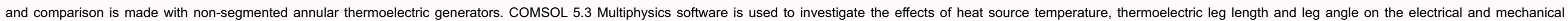

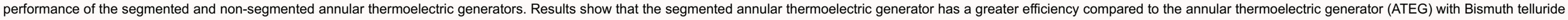

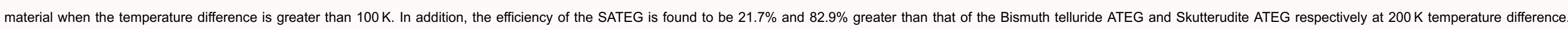

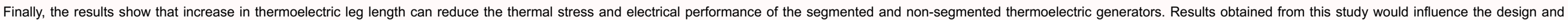
optimization of segmented annular thermoelectric generators.

Keywords: Segmented thermoelectric generator; Annular thermoelectric generator; Finite element method; Power generation; Thermal stress

\section{Nomenclature}

r

radius, $\mathrm{mm}$

angle of a single thermoelectric leg, degree

$\theta_{2}$

half of the angle between two legs, degree

C 2019. This manuscript version is made available under the CC-BY-NC-ND

4.0 license http://creativecommons.org/licenses/by-nc-nd/4.0/ 
angle between outer copper and legs, degree

$\theta$

total leg angle, degree

L

length of thermoelectric legs, $\mathrm{mm}$

$\mathrm{n}_{\mathrm{h}}$

hot segment n-type material

$\mathrm{n}_{\mathrm{c}}$

cold segment $n$-type material

$\mathrm{p}_{\mathrm{h}}$

hot segment p-type material

$\mathrm{p}_{\mathrm{c}}$

cold segment p-type material

$Q_{\text {in }}$

input heat flux, $W / \mathrm{m}^{2}$

$\mathrm{Q}_{\text {out }}$

output heat flux, $W / \mathrm{m}^{2}$

$\mathrm{R}_{\mathrm{L}}$

load resistance, $\Omega$

$\mathrm{P}_{\text {out }}$

output power, W

$c_{P}$

specific heat capacity, $\mathrm{J} / \mathrm{kg} / \mathrm{K}$

T

temperature, $\mathrm{K}$

E

young's modulus, GPa 
figure of merit

Greek symbols

a

seebeck coefficient

$\eta$

efficiency, \%

$\sigma$

electrical conductivity, $S / m$

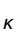

thermal conductivity, $\mathrm{W} / \mathrm{m} / \mathrm{K}$

$\rho_{d}$

density, $\mathrm{Kg} / \mathrm{m}^{3}$

$\rho$

electrical resistivity, $\Omega \mathrm{m}$

Abbreviations

SATEG

segmented annular thermoelectric generator

ATEG

annular thermoelectric generator

TEG

thermoelectric generator

$\mathrm{Bi}_{2} \mathrm{Te}_{3}$

Bismuth telluride

$\mathrm{CoSb}_{3}$

Cobalt antimony

$\mathrm{PbTe}$

lead telluride 


\section{Introduction}

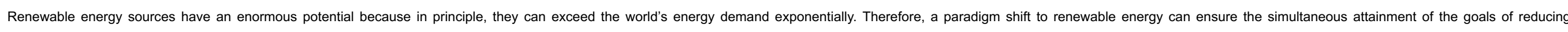

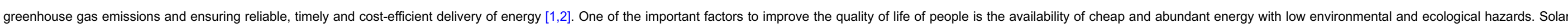

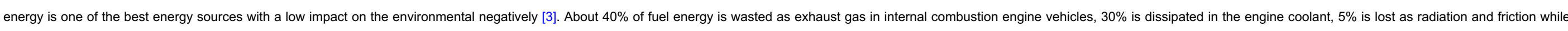

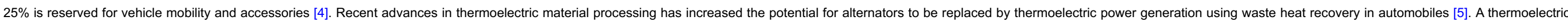

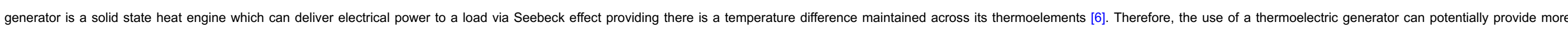

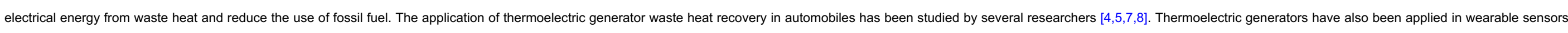
[9-12], micropower generation [13], wireless sensor network [14], space power [15] and buildings [16].

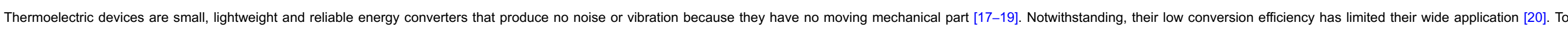

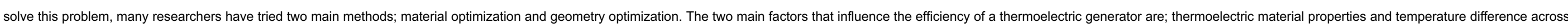

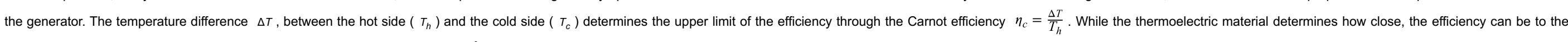

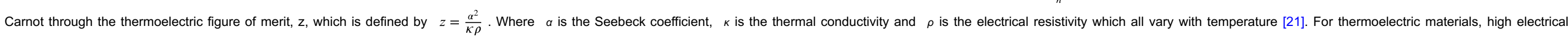
conductivity, low thermal conductivity and high Seebeck coefficient is desirable [22]. Thus, materials with high figure of merit can increase the efficiency of thermoelectric generators.

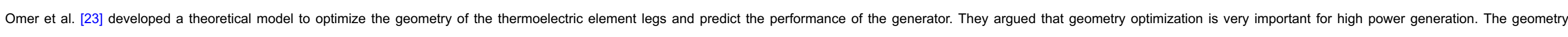

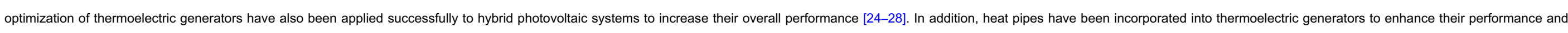
reduce cost [29-32]. These studies have shown the importance of optimizing the geometry of thermoelectric elements for improved performance.

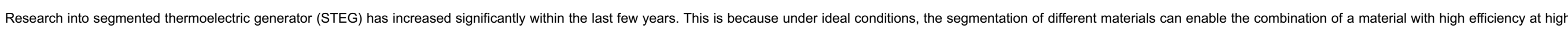

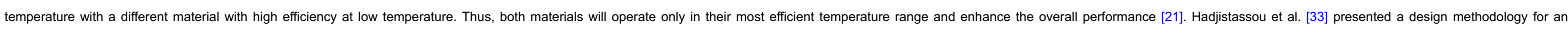

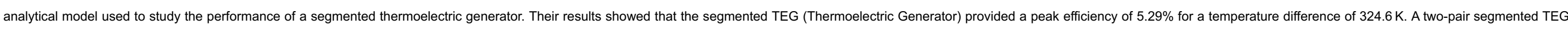

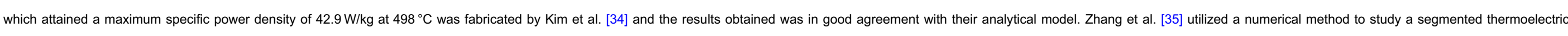

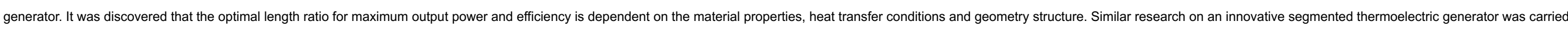

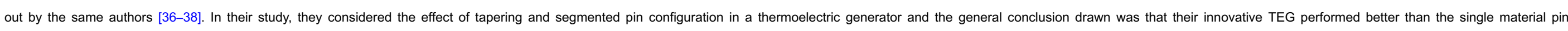
configuration TEG. In one case, they found that the extended leg configuration increased thermoelectric efficiency by $8 \%[38]$.

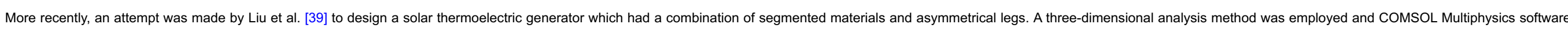

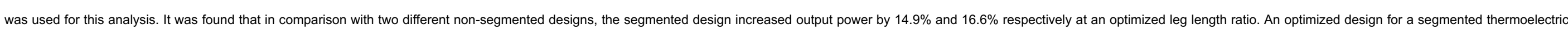

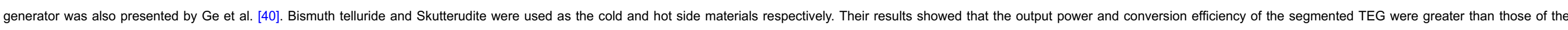

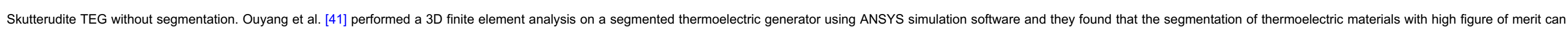
offer $<1 \$ / W$ cost-performance ratio. 


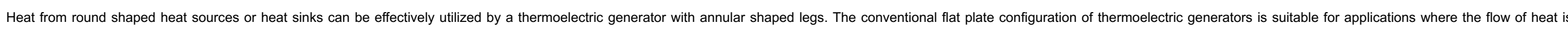

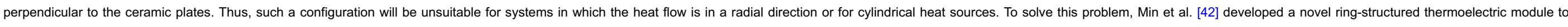

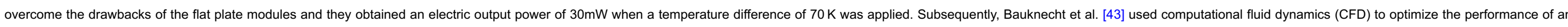

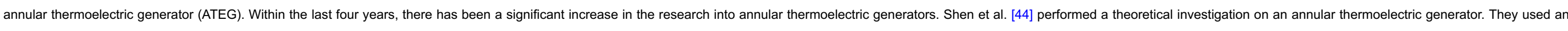

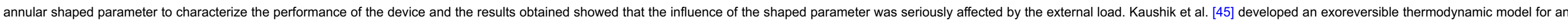

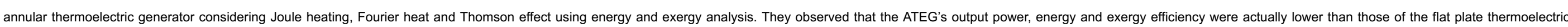

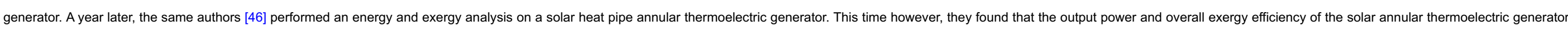

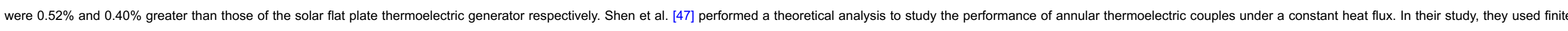

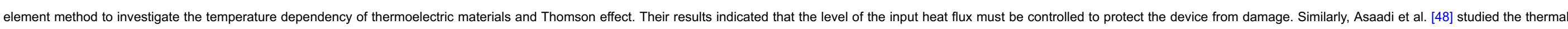
and electrical performance of an ATEG under pulsed heat flux using finite element method. They concluded that transient pulsed heating enhanced the output power and efficiency of the ATEG compared to constant steady state heating.

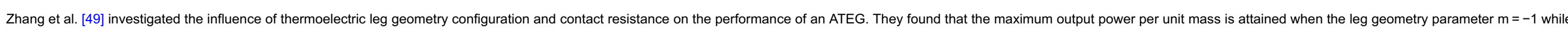

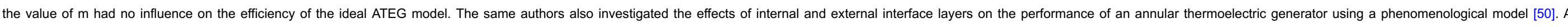

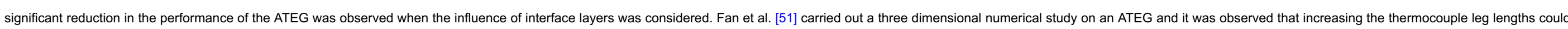

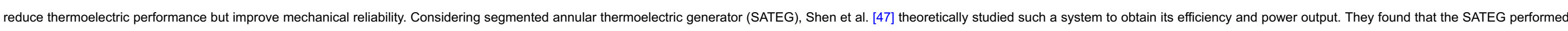
better than the ATEG as the temperature ratio was being increased.

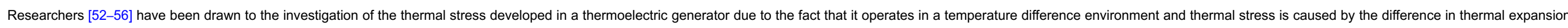

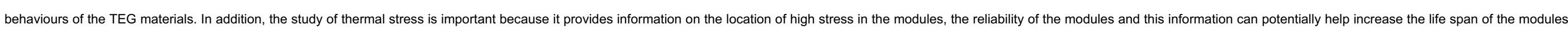

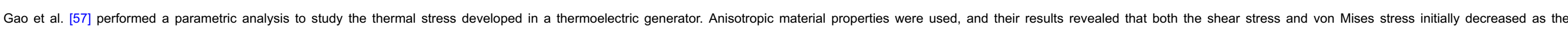

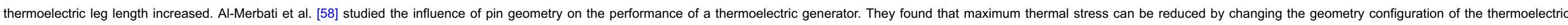

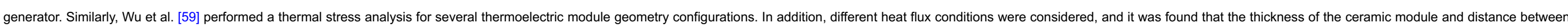
thermoelectric legs influenced on the thermal stress in the module. Erturun et al. [60] also found that varying leg geometry can help reduce the thermal stress developed in a thermoelectric generator.

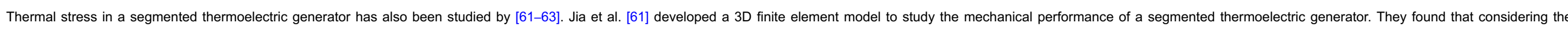

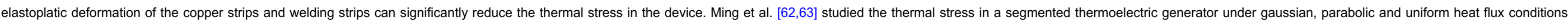
Results obtained revealed that the position between the hot end of the alumina and copper have the highest possibility to crack in the module.

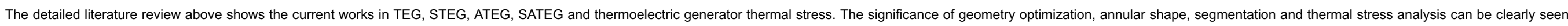

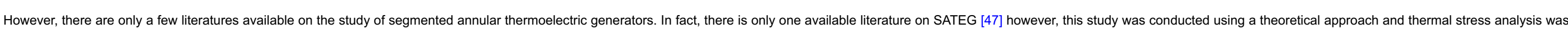

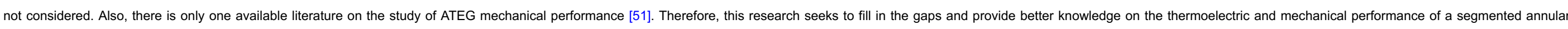

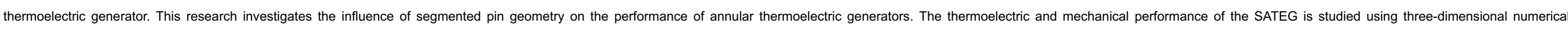

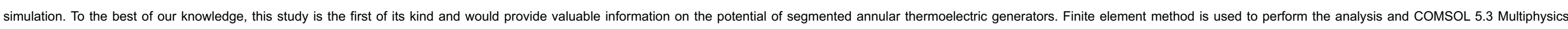

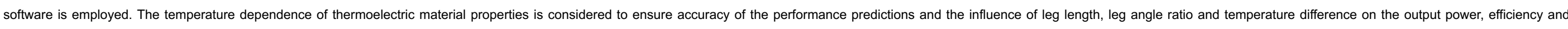
thermal stress of the SATEG are studied. Finally, a comparison between the performance of the SATEG and ATEG is presented.

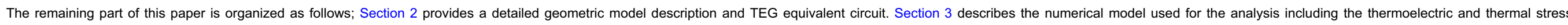
analyses, material properties, boundary conditions, computation procedure and model validation. Section 4 describes the results obtained and analysis of the results. Finally, Section 5 provides the conclusions drawn from this study.

\section{Geometric model description}

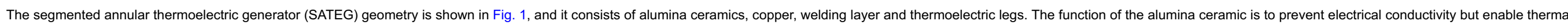




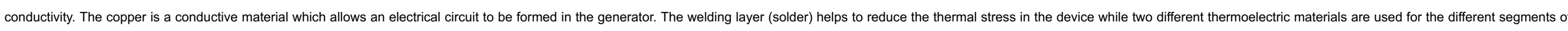

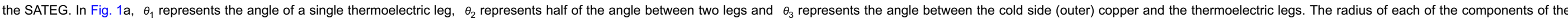

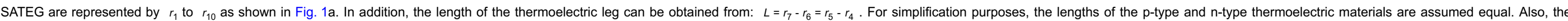

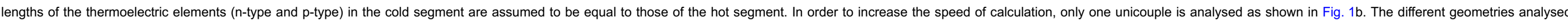

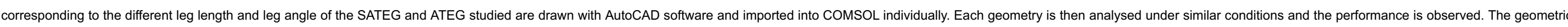

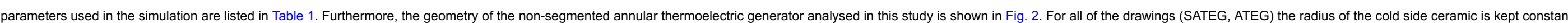

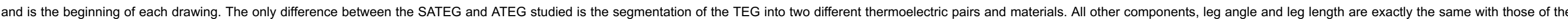

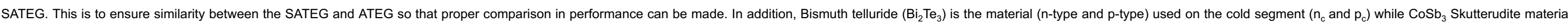

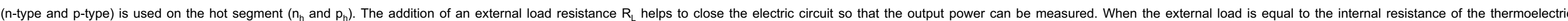
generator, maximum power can be generated 


$$
\text { 产 }
$$




\begin{tabular}{|c|c|c|c|c|c|c|c|c|c|c|c|c|c|}
\hline $\mathrm{Bi}_{2} \mathrm{Te}_{3}$ Legs & - & - & - & - & - & Depends on study & - & - & - & - & $r_{7}-r_{6}$ & 1 & - \\
\hline $\mathrm{CoSb}_{3}$ Legs & - & - & - & Depends on study & Depends on study & - & - & - & - & - & $r_{5}-r_{4}$ & 1 & - \\
\hline$\theta_{1}$ & - & - & - & - & - & - & - & - & - & - & - & - & Depends on study \\
\hline$\theta_{2}$ & - & - & - & - & - & - & - & - & - & - & - & - & Depends on study \\
\hline$\theta_{3}$ & - & - & - & - & - & - & - & & - & - & - & - & 1 \\
\hline
\end{tabular}

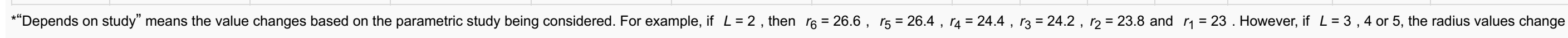
accordingly.

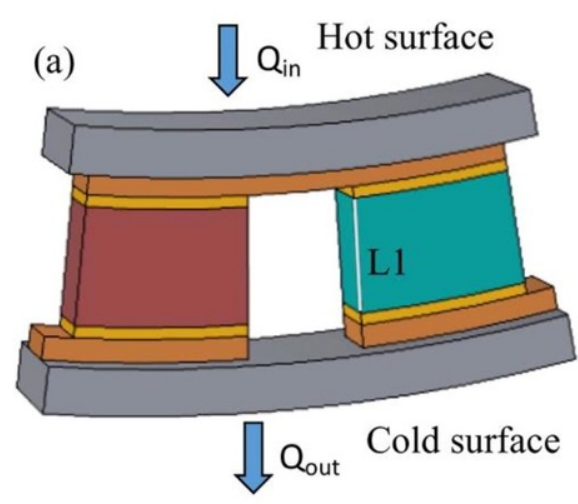

(b)

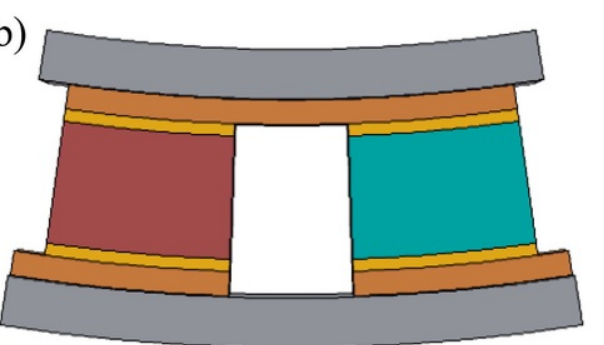

\subsection{Thermoelectric generator equivalent electrical circuit}

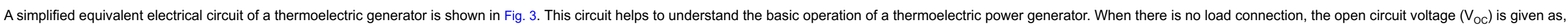
$V_{O C}=\alpha \Delta T$

where $a$ is the Seebeck coefficient and $\Delta T=T_{h}-T_{C}$ is the temperature difference between the hot side and cold side of the thermoelectric generator. 


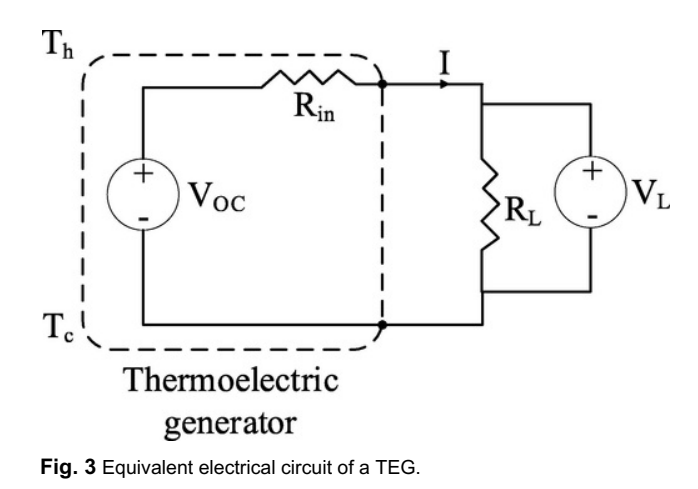

When an external load resistance $\left(R_{L}\right)$ is connected, the output voltage of the thermoelectric generator $\left(V_{L}\right)$ is given as,

$V_{L}=V_{O C}-R_{i n} I=R_{L} I$

where $R_{i n}$ is the internal resistance of the TEG and $I$ is the TEG current which is given as,

$I=\frac{V_{O C}}{R_{i n}+R_{L}}=\frac{\alpha \Delta T}{R_{i n}+R_{L}}$

The output power of the TEG $\left(P_{L}\right)$ can thus be obtained as,

$P_{L}=V_{L} I=R_{L} I^{2}=\frac{R_{L} \cdot \alpha^{2} \cdot \Delta T^{2}}{\left(R_{i n}+R_{L}\right)^{2}}$

(4)

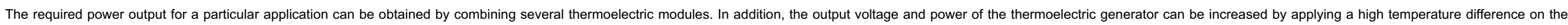
TEG and by matching the external load resistance to the internal resistance of the TEG.

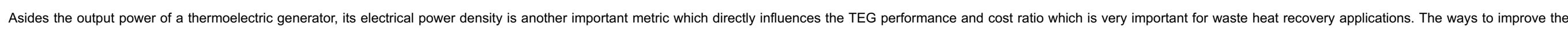

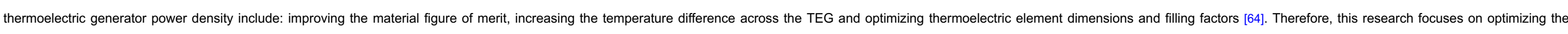
thermoelectric element dimensions.

\section{Numerical model}

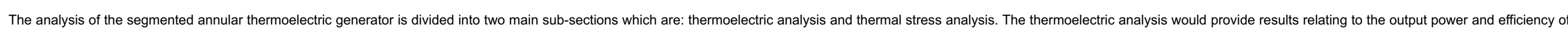
the system while the thermal stress analysis would provide results relating to the mechanical performance of the system.

\subsection{Governing equations of thermoelectric analysis}

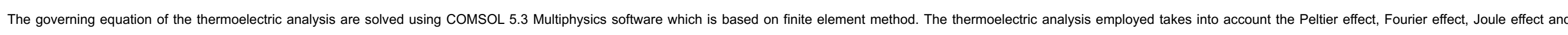
Thomson effect.

The heat flow equation in the thermoelectric analysis can be expressed as [20]:

$$
\rho_{d} C_{p} \frac{\partial T}{\partial t}+\nabla \cdot \vec{q}=\dot{q}
$$

where $\rho_{d}$ is the density, $C_{p}$ is specific heat capacity, $T$ is temperature, $\vec{q}$ is heat flux vector and $\dot{q}$ is the heat generation rate per unit volume.

The electric charge continuity equations can be expressed as 


$$
\nabla \cdot\left(\vec{J}+\frac{\partial \vec{D}}{\partial t}\right)=0
$$

where $\vec{J}$ is the electric current density vector and $\vec{D}$ is the electric flux density vector.

Eqs. (5) and (6) are coupled using the following thermoelectric constitutive equations [65],

$\vec{q}=T[\alpha] \cdot \vec{J}-[\kappa] \cdot \nabla T$

$\vec{J}=[\sigma] \cdot(\vec{E}-[\alpha] \cdot \nabla T)$

where $[\alpha]$ is the Seebeck coefficient matrix, $[k]$ represents the thermal conductivity matrix and $[\sigma]$ is the electrical conductivity matrix.

$\vec{E}=-\nabla \varphi$

where $\vec{E}$ is the electric field intensity vector and $\varphi$ is the electric scalar potential.

The coupled thermoelectric equations can be obtained by combining the above equations as,

$\rho_{d} C_{p} \frac{\partial T}{\partial t}+\nabla \cdot(T[\alpha] \cdot \vec{J})-\nabla \cdot([\alpha] \cdot \nabla T)=\dot{q}$

$\nabla \cdot\left([\varepsilon] \cdot \nabla \frac{\partial \varphi}{\partial t}\right)+\nabla \cdot([\sigma] \cdot[\alpha] \cdot \nabla T)+\nabla \cdot([\sigma] \cdot \nabla \varphi)=0$

where $[\varepsilon]$ represents the dielectric permittivity matrix.

Finally, the coupled thermoelectric governing equations can rewritten as,

$\nabla \cdot(T \alpha \vec{J})-\nabla \cdot(\lambda \nabla T)=\dot{q}$

$\nabla \cdot(\sigma \alpha \nabla \mathrm{T})+\nabla \cdot(\sigma \nabla \varphi)=0$

\subsection{Governing equations of thermal stress analysis}

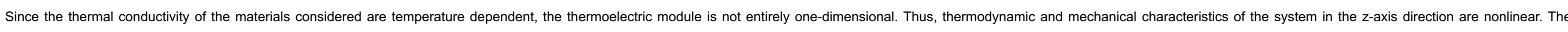
temperature field is used to calculate the thermal stress field since temperature influences deformations in the system.

The thermodynamic equation can be express as [59],

$$
\frac{\partial}{\partial x}\left[k \frac{\partial T}{\partial x}\right]+\frac{\partial}{\partial y}\left[k \frac{\partial T}{\partial y}\right]+\frac{\partial}{\partial z}\left[k \frac{\partial T}{\partial y}\right]=0
$$

where $k=f(T)$ and $T=f(x, y, z)$. The temperature field is obtained by the numerical simulation and is used in the thermal stress analysis.

Thermal stress is generated due to the uneven expansion of the materials making up the thermoelectric generator. The equations governing the displacement-strain relations for the thermal stress can be expressed as [62],

$$
\begin{aligned}
& \bar{\varepsilon}_{x x}=\frac{\partial \bar{u}}{\partial \bar{x}}, \bar{\varepsilon}_{y y}=\frac{\partial \bar{v}}{\partial \bar{y}}, \bar{\varepsilon}_{z z}=\frac{\partial \bar{w}}{\partial \bar{z}} \\
& \bar{\varepsilon}_{x y}=0.5\left(\frac{\partial \bar{u}}{\partial \bar{y}}+\frac{\partial \bar{v}}{\partial \overline{\bar{x}}}\right), \bar{\varepsilon}_{y z}=0.5\left(\frac{\partial \bar{w}}{\partial \bar{y}}+\frac{\partial \bar{v}}{\partial \bar{z}}\right), \bar{\varepsilon}_{x z}=0.5\left(\frac{\partial \bar{w}}{\partial \bar{x}}+\frac{\partial \bar{u}}{\partial \bar{z}}\right)
\end{aligned}
$$

The stress-strain relation can be expressed in a dimensionless form using a nonsymmetrical Jacobian matrix as, 


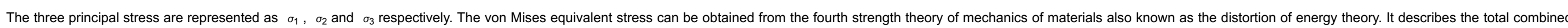
stresses in all three dimensions as,

$$
\sigma=\sqrt{\frac{\left[\left(\sigma_{1}-\sigma_{2}\right)^{2}+\left(\sigma_{2}-\sigma_{3}\right)^{2}+\left(\sigma_{3}-\sigma_{1}\right)^{2}\right]}{2}}
$$

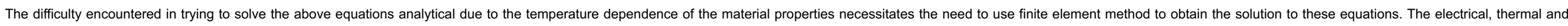
mechanical behaviours of the thermoelectric generator can be obtained from the coupled equations described above.

\subsection{Material properties}

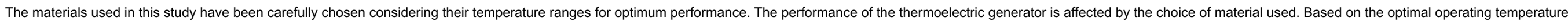

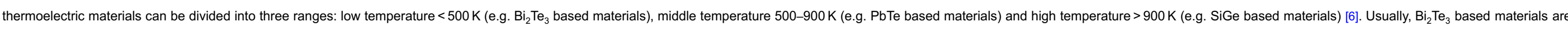

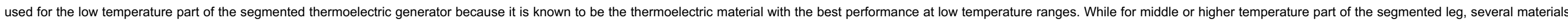

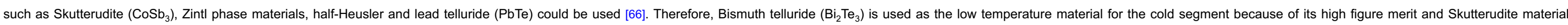

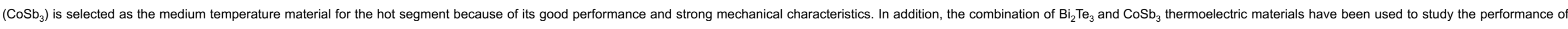
SATEG [47], STEG [20,61] and favourable results were obtained.

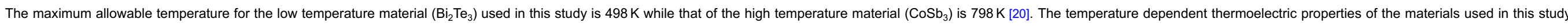
are shown in Fig. 4 while the remaining material properties used in the numerical simulation are listed in Table 2. 

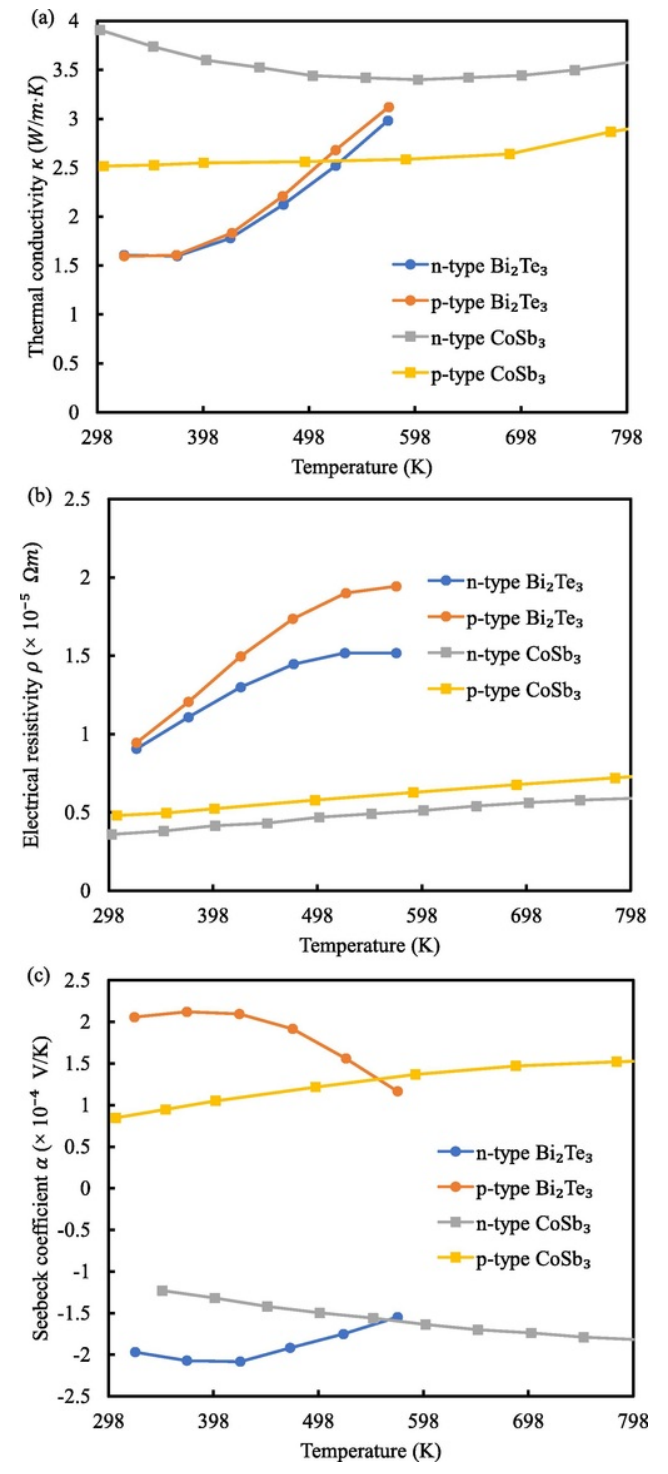

Fig. 4 Temperature dependent thermoelectric properties [47]: (a) thermal conductivity, (b) electrical resistivity, (c) Seebeck coefficient.

Table 2 Properties of other materials used in numerical simulation $[51,57,58,67-69]$.

\begin{tabular}{|c|c|c|c|c|c|c|}
\hline Materials & $\begin{array}{l}\text { Thermal } \\
\text { conductivity, } \\
\kappa\left(\frac{W}{m \cdot K}\right)\end{array}$ & $\begin{array}{c}\text { Electrical } \\
\text { conductivity, } \\
\sigma\left(\frac{S}{m}\right)\end{array}$ & $\begin{array}{c}\text { Specific } \\
\text { heat } \\
\text { capacity, } \\
C_{p}\left(\frac{J}{k g \cdot K}\right)\end{array}$ & $\begin{array}{l}\text { Density, } \\
\rho_{d}\left(\frac{\mathrm{kg}}{\mathrm{m}^{3}}\right)\end{array}$ & & Coefficient of thermal expansion, $\left(\frac{1}{K}\right.$ \\
\hline Ceramic & 25 & $1 e-12$ & 800 & 3970 & $0.68 e-5$ & \\
\hline Copper & 385 & $5.9 \mathrm{e} 7$ & 386 & 8930 & $1.7 e-5$ & \\
\hline
\end{tabular}


Solder

$\mathrm{Bi}_{2} \mathrm{Te}_{3}$

2.7e-5

$0.8 \mathrm{e}-5$ 


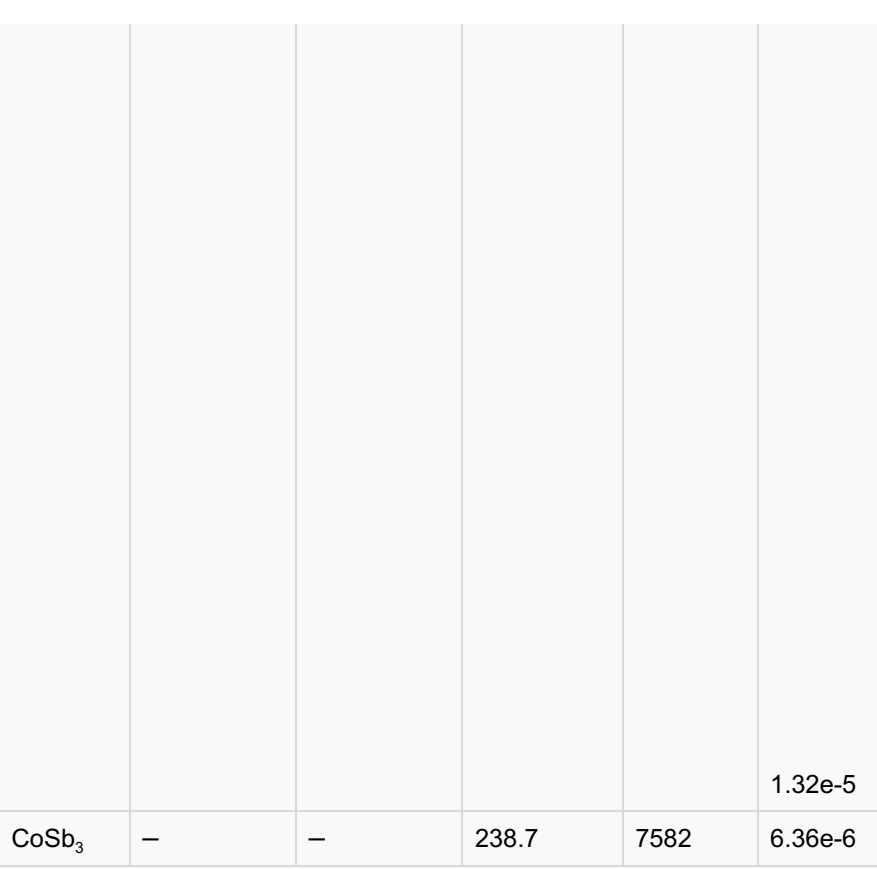

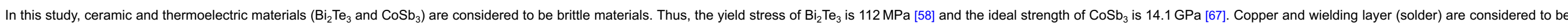
elastoplastic materials. Therefore, the yield stress and tangential modulus of copper $70 \mathrm{MPa}$ and $24 \mathrm{GPa}$ respectively. While those of solder are $26 \mathrm{MPa}$ and $8.9 \mathrm{GPa}$ respectively too [51].

\subsection{Boundary conditions}

The basic assumptions made in this numerical simulation to simplify the model without significant deviations from the real condition are:

(a) All other surfaces except the hot and cold surfaces are adiabatic.

(b) Electrical contact resistance and thermal contact resistance are ignored.

(c) Heat losses due to convection and radiation on all surfaces are neglected.

(d) The heat source (hot surface) and heat sink (cold surface) are considered as thermal boundary conditions with fixed temperature values.

(e) A fixed constraint boundary condition is applied on the hot surface of the thermoelectric generator while all other boundaries are free.

(f) No difference in properties as a function of position exist.

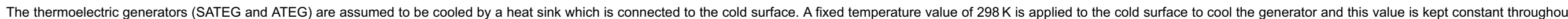
the study. This can be represented as,

$T_{c}=298 K$

(15 (Kindly change this equation (15) to (19) )

\subsection{Computation procedure}

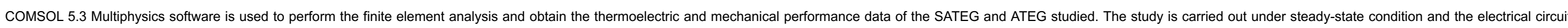

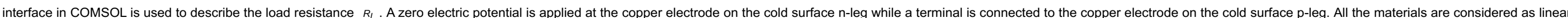




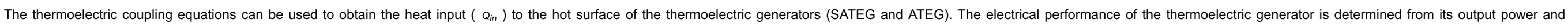
efficiency, which are defined as [51],

$P_{\text {out }}=I^{2} R_{L}$

(16)(Kindly change this equation (16) to (20))

$\eta=\frac{P_{\text {out }}}{Q_{\text {in }}}$

(17) (Kindly change this equation (17) to (21)

where $P_{\text {out }}$ is the output power and $I$ is the circuit electric current.

The total leg angle of the thermoelectric generator can be expressed as,

$\theta=\theta_{1}+\theta_{2}$

(18)(Kindly change this equation (18) to (22)

\subsection{Model validation}

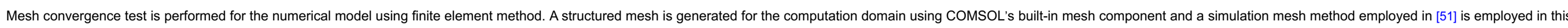

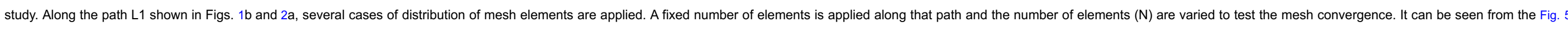
that the mesh convergences and the results are almost identical therefore, $\mathrm{N}=20$ is selected in all simulations (SATEG and ATEG) to ensure accuracy and convergence.
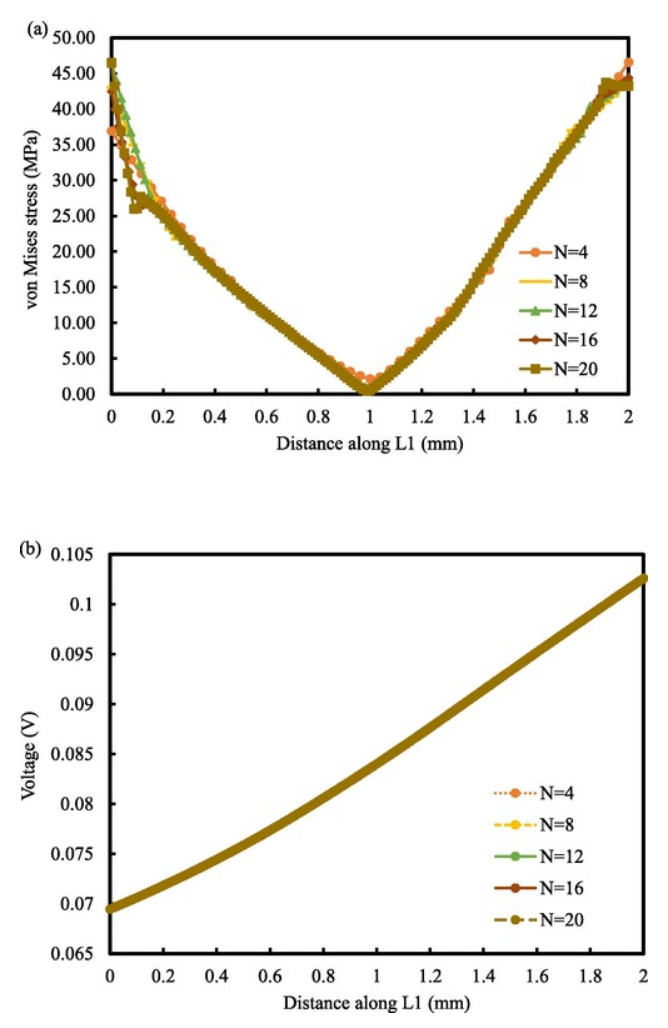

Fig. 5 Mesh convergence test for the SATEG's (a) von Mises stress (thermal analysis) (b) voltage (thermoelectric analysis).

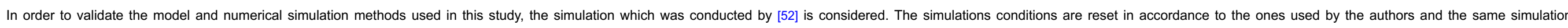




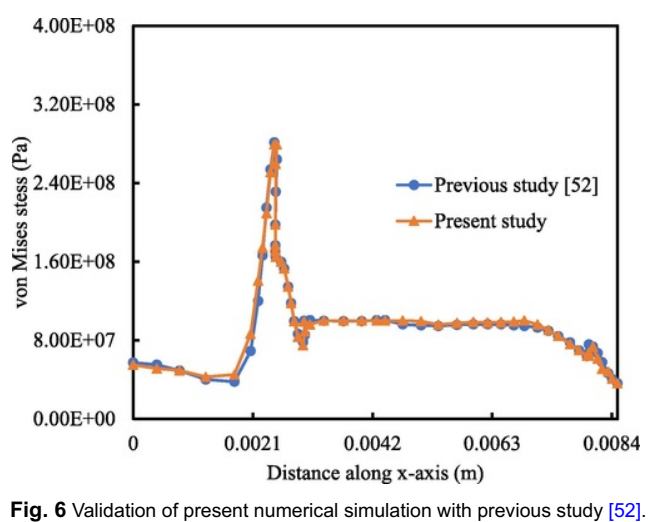

Fig. 6 Validation of present numerical simulation with previous

\section{Results and discussion}

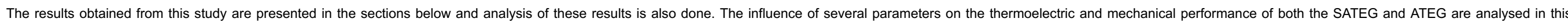
section.

\subsection{Effect of heat source temperature}

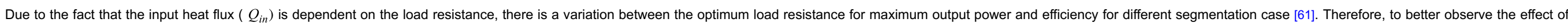

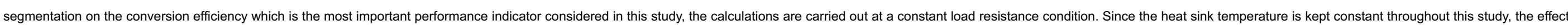

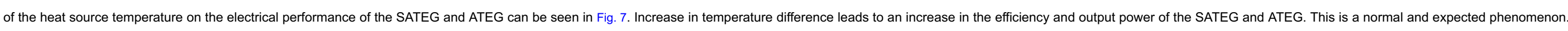

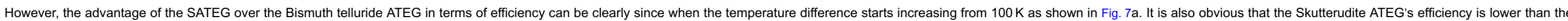

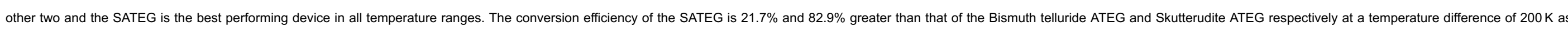

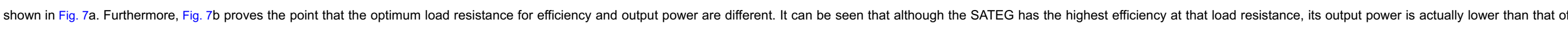

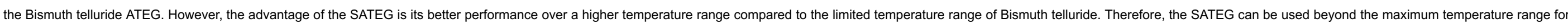
Bismuth telluride $(498 \mathrm{~K})$ thus, it has a higher potential compared to the other two single-material ATEG for recovering waste at a large temperature difference. 


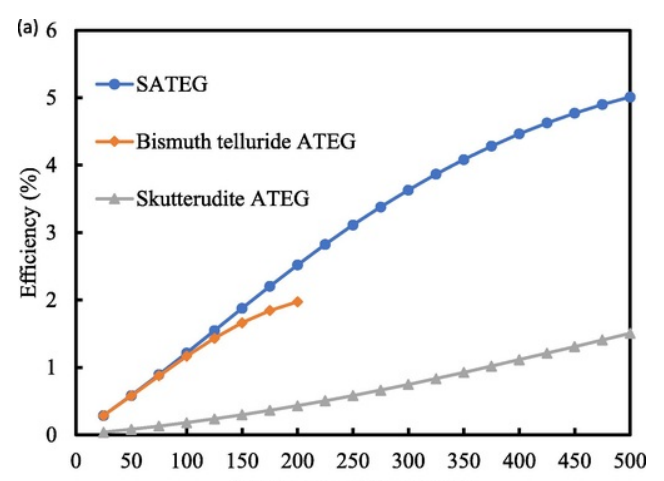

Temperature difference $(\mathrm{K})$

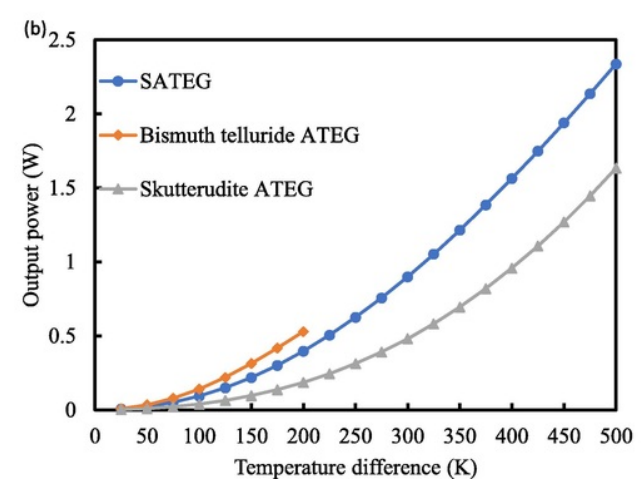

Fig. 7 Variation of SATEG and ATEG (a) efficiency and (b) output power with temperature difference when $L=2, \theta_{1}=6, \theta_{2}=2$ and $R_{L}=0.01 \Omega$

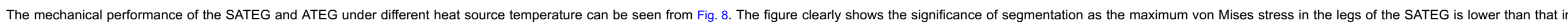

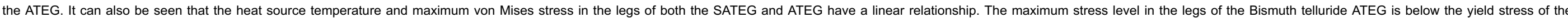

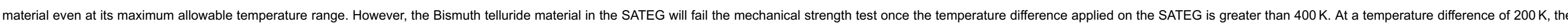

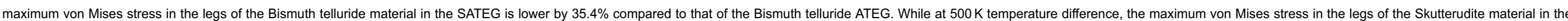
SATEG is lower by $5.7 \%$ compared to that of the Skutterudite ATEG. Therefore, SATEG has a better mechanical performance compared to the ATEG as shown in Fig. 8.

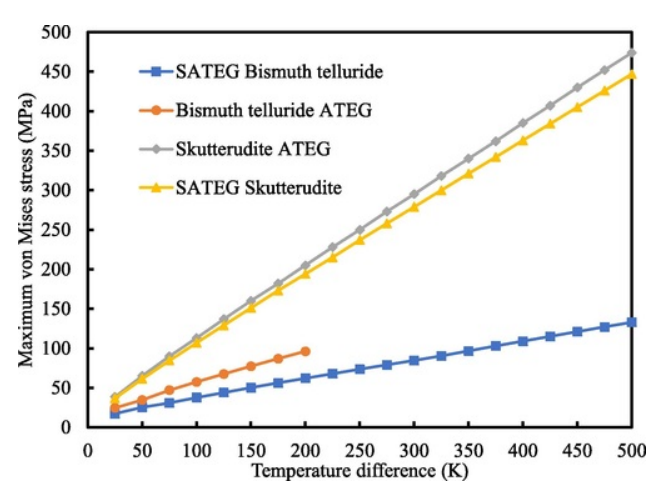




\subsection{Effect of thermoelectric leg length}

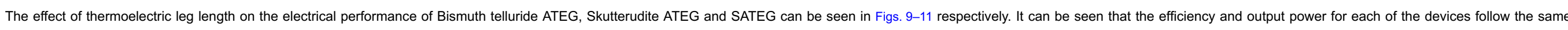

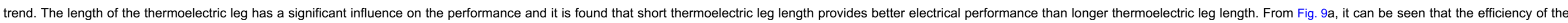

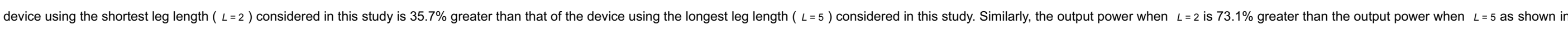

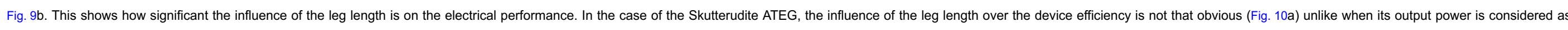

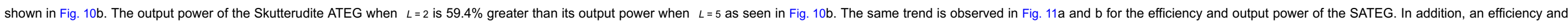
output power enhancement of $45.3 \%$ and $79.1 \%$ respectively is observed when the SATEG thermoelectric leg length is reduced from $L=5$ to $L=2$.
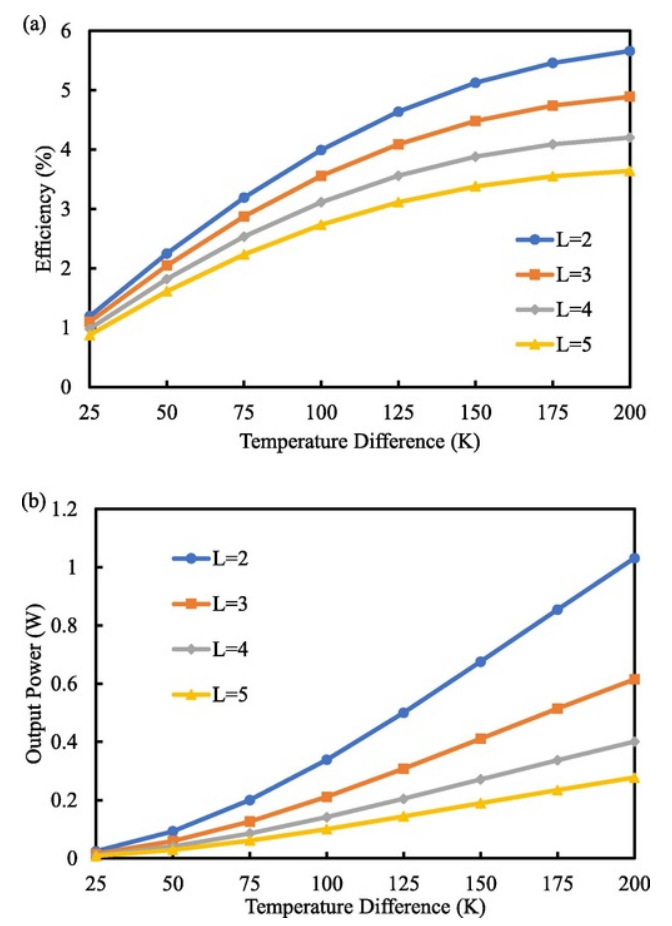

Fig. 9 Variation of Bismuth telluride ATEG leg length with (a) Efficiency and (b) Output power when $\theta_{1}=3, \theta_{2}=3$, and $R_{L}=0.001 \Omega$. 

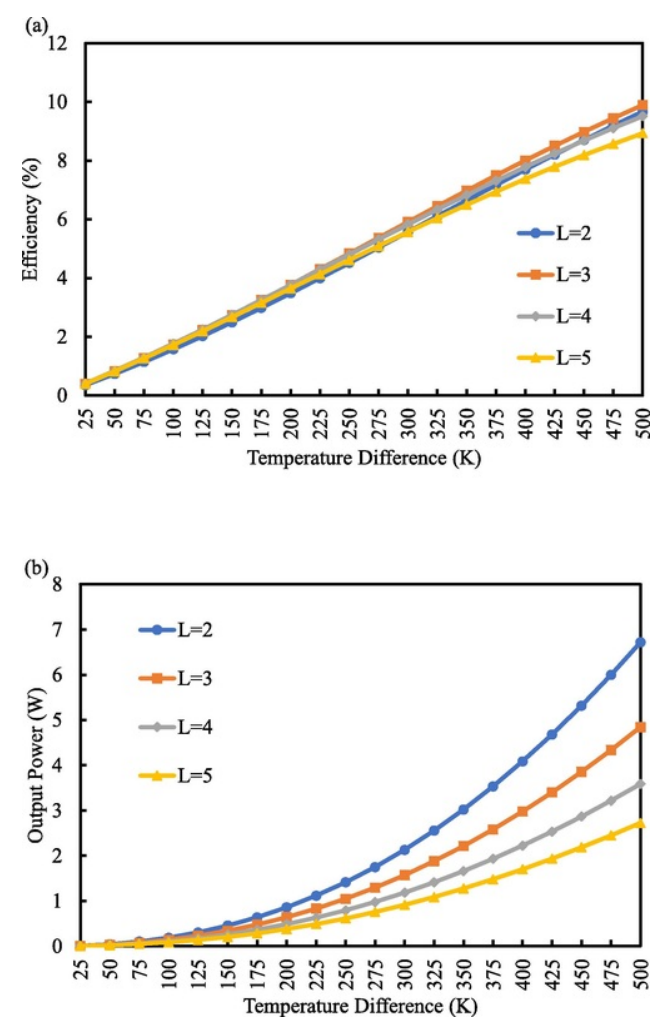

Fig. 10 Variation of Skutterudite ATEG leg length with (a) Efficiency and (b) Output power when $\theta_{1}=3, \theta_{2}=3$, and $R_{L}=0.001 \Omega$ 

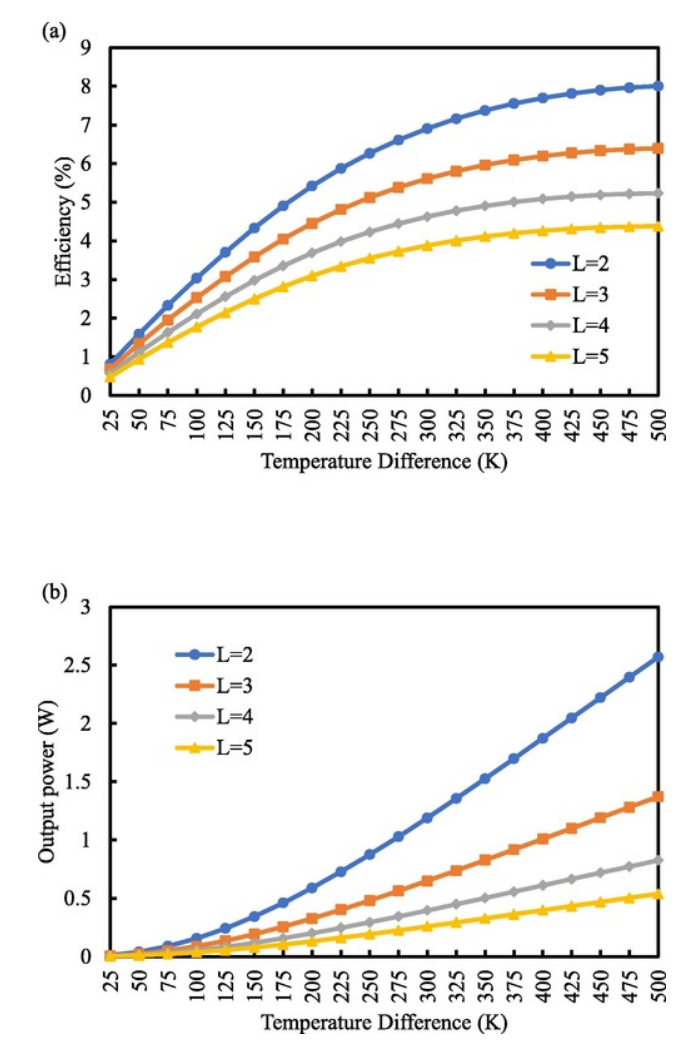

Fig. 11 Variation of SATEG leg length with (a) Efficiency and (b) Output power when $\theta_{1}=3, \theta_{2}=3$, and $R_{L}=0.001 \Omega$

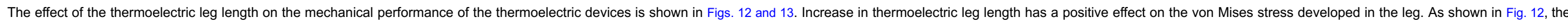

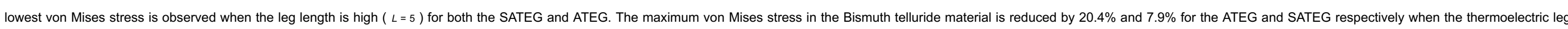

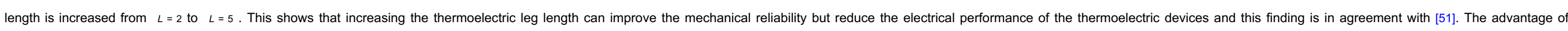

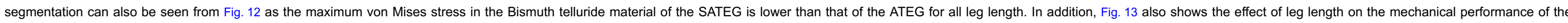

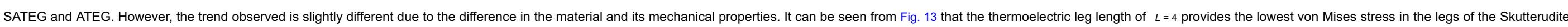
material of the SATEG.

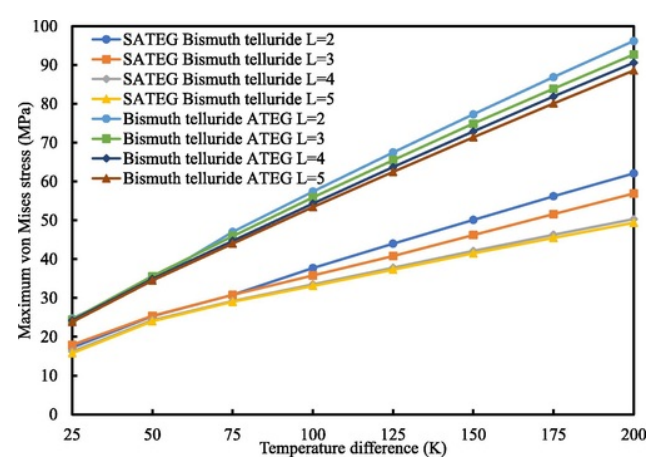




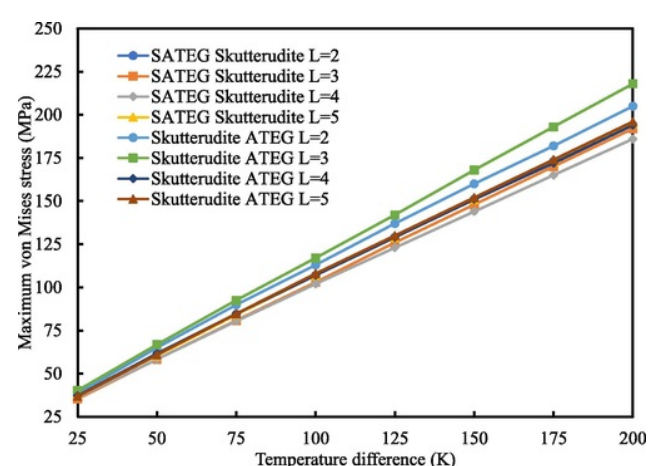

Fig. 13 Effect of Skutterudite thermoelectric leg length in SATEG and ATEG when $\theta_{1}=6$ and $\theta_{2}=2$.

\subsection{Effect of thermoelectric leg angle}

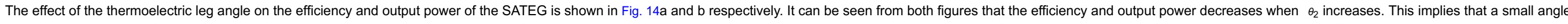

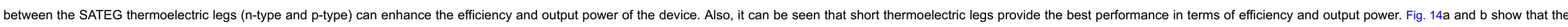

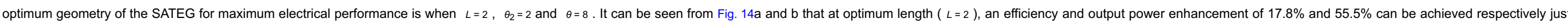
by reducing the angle between the thermoelectric legs from $\theta_{2}=5$ to $\theta_{2}=2$. 

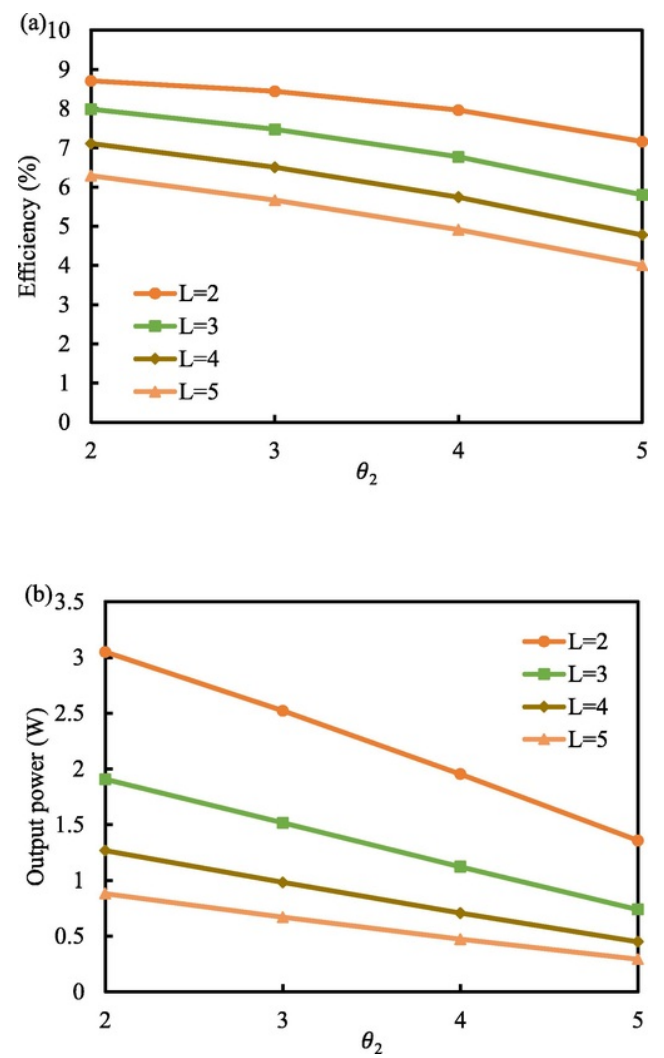

Fig. 14 Variation of leg angle with SATEG (a) efficiency and (b) output power when $\theta=8, T_{h}=623 K$ and $R_{L}=0.001$

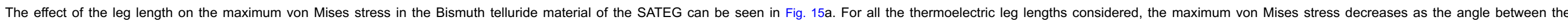

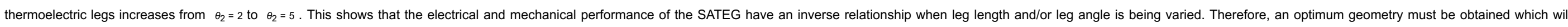

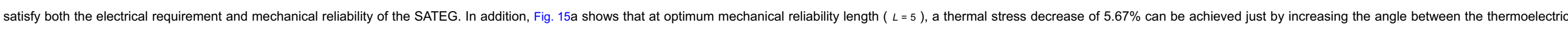

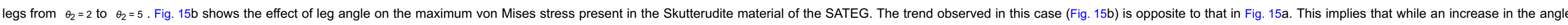

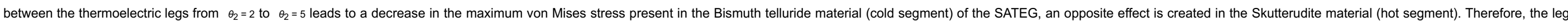
angle and leg length of the segmented annular thermoelectric generator must be carefully chosen to satisfy low stress requirements in both segments of the device. 

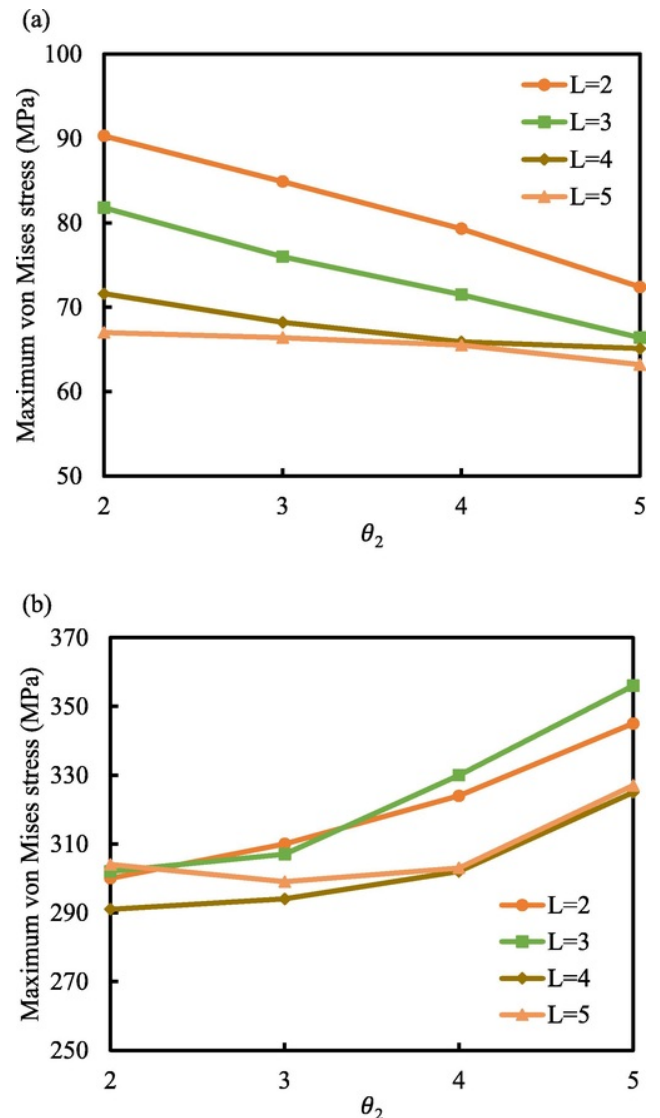

Fig. 15 Variation of leg angle with maximum von Mises stress in (a) Bismuth telluride and (b) Skutterudite materials of the SATEG when $\theta=8$ and $T_{h}=623 \mathrm{~K}$.

\subsection{SATEG von Mises stress nephogram}

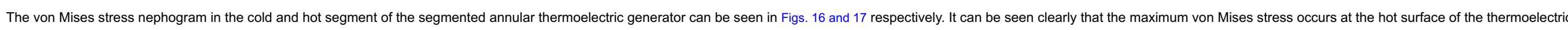

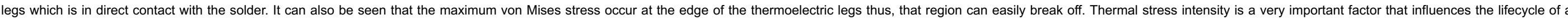

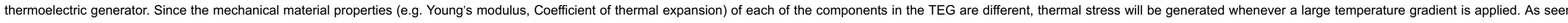

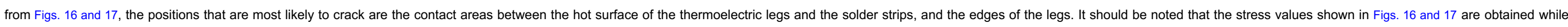
considering the elastoplastic characteristics of the copper and solder materials. If this is not considered, the maximum von Mises stress in the legs will be higher 
(a)

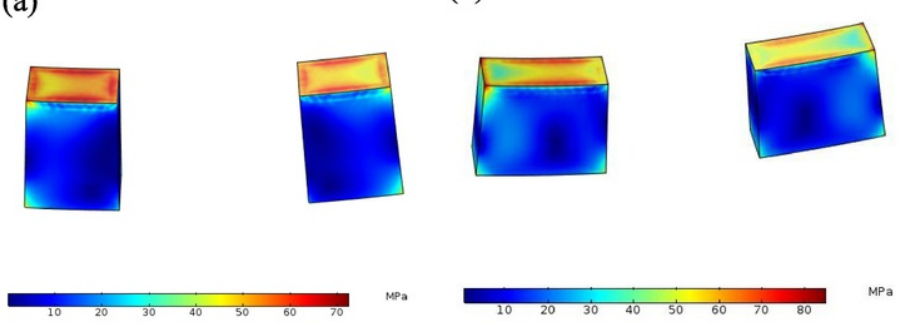

(d)

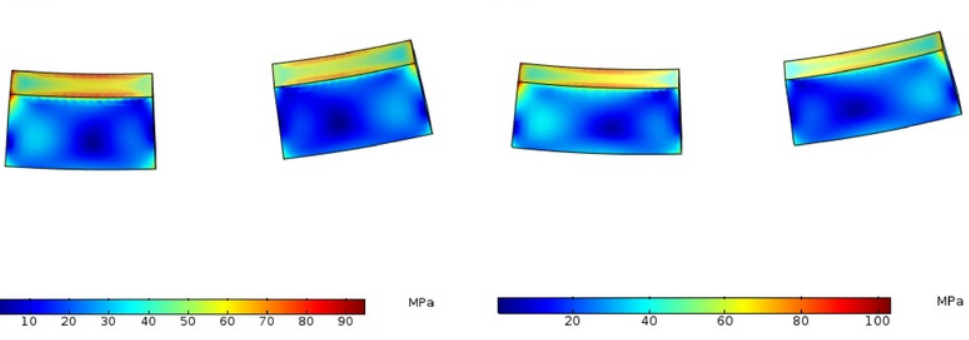

Fig. 16 Nephogram of the von Mises stress in Bismuth telluride material of the SATEG when $L=2, T_{h}=623 \mathrm{~K}, \theta_{2}=3$, (a) $\theta_{1}=3$, (b) $\theta_{1}=5$, (c) $\theta_{1}=7$ and (d) $\theta_{1}=9$. 
(b)
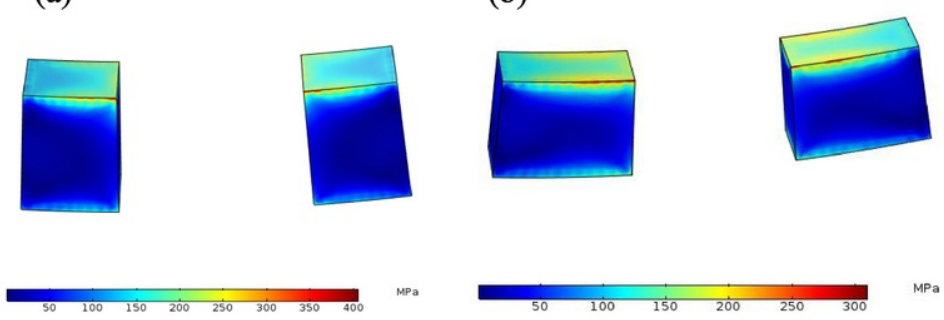

(c)

(d)

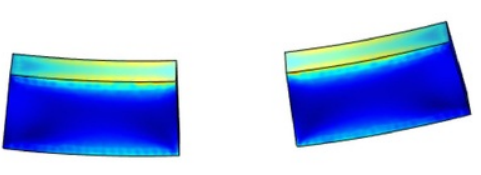

Fig. 17 Nephogram of the von Mises stress in Skutterudite material of the SATEG when $L=2, T_{h}=623 K, \theta_{2}=3$, (a) $\theta_{1}=3$, (b) $\theta_{1}=5$, (c) $\theta_{1}=7$ and (d) $\theta_{1}=9$.

\section{Conclusion}

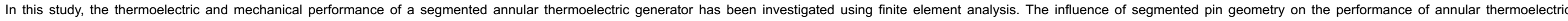

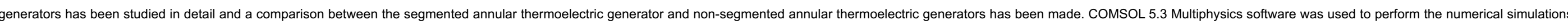

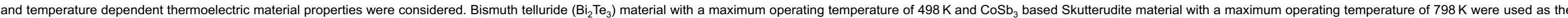

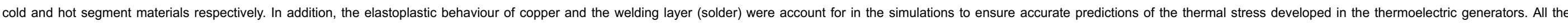

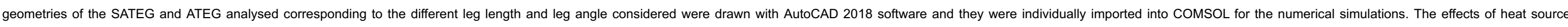

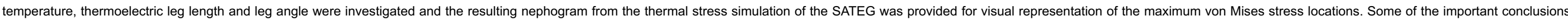
from this research are:

1. The advantage of the SATEG over the Bismuth telluride ATEG in terms of efficiency becomes clear when the temperature difference is greater than $100 \mathrm{~K}$.

2. The efficiency of the SATEG is $21.7 \%$ and $82.9 \%$ greater than the efficiency of the Bismuth telluride ATEG and Skutterudite ATEG respectively at $200 \mathrm{~K}$ temperature difference.

3. The maximum von Mises stress in the legs of the Bismuth telluride material in the SATEG is $35.4 \%$ lower than that of the Bismuth telluride ATEG at $200 \mathrm{~K}$ temperature difference.

4. Efficiency and output power enhancement of $45.3 \%$ and $79.1 \%$ respectively were observed when the SATEG leg length was reduced from $L=5$ to $L=2$. Therefore, shorter thermoelectric legs provide better electrical performance.

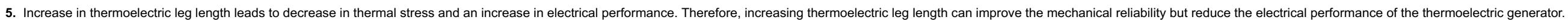


7. The Maximum von Mises stress in the SATEG decreases as the angle between the thermoelectric legs increases from $\theta_{2}=2$ to $\theta_{2}=5$ for all leg lengths considered.

8. The positions most likely to crack are the contact areas between the hot surface of the thermoelectric legs and the solder strips, and the edges of the legs.

\section{Conflict of interest}

None.

\section{Acknowledgement}

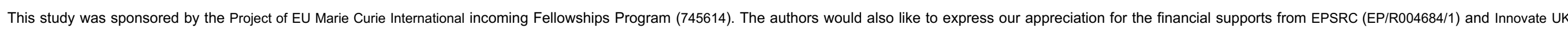

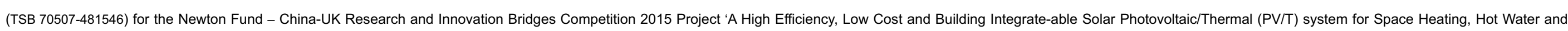
Power Supply' and DongGuan Innovation Research Team Program (No. 2014607101008).

\section{References}

[1] O. Ellabban, H. Abu-Rub and F. Blaabjerg, Renewable energy resources: current status, future prospects and their enabling technology, Renew Sustain Energy Rev 39, $2014,748-764$.

[2] N.L. Panwar, S.C. Kaushik and S. Kothari, Role of renewable energy sources in environmental protection: a review, Renew Sustain Energy Rev 15, 2011, 1513-1524.

[3] K.H. Solangi, M.R. Islam, R. Saidur, N.A. Rahim and H. Fayaz, A review on global solar energy policy, Renew Sustain Energy Rev 15, 2011, $2149-2163$.

[4] J. Yang, Potential applications of thermoelectric waste heat recovery in the automotive industry, Int Conf Thermoelectr ICT Proc 2005, 2005, 155-159.

[5] K.M. Saqr, M.K. Mansour and M.N. Musa, Patient expectations for health supervision advice in continuity clinic: experience from a teaching hospital in Thailand, Int $J$ Automot Technol 9, 2008 , 155-160.

[6] D.M. Rowe, Thermoelectrics, an environmentally-friendly source of electrical power, Renew Energy 16, 1999, 1251-1256.

[7] Y.Y. Hsiao, W.C. Chang and S.L. Chen, A mathematic model of thermoelectric module with applications on waste heat recovery from automobile engine, Energy 35, 2010, 1447-1454.

[8] G. Shu, X. Ma, H. Tian, H. Yang, T. Chen and X. Li, Configuration optimization of the segmented modules in an exhaust-based thermoelectric generator for engine waste heat recovery, Energy 160, $2018,612-624$.

[9] L. Francioso, C. De Pascali, I. Farella, C. Martucci, P. Creti, P. Siciliano, et al., Flexible thermoelectric generator for wearable biometric sensors, Proc IEEE Sensors 196, 2010, 747-750.

[10] S.J. Kim, J.H. We and B.J. Cho, A wearable thermoelectric generator fabricated on a glass fabric, Energy Environ Sci 7, 2014, 1959-1965.

[11] F. Suarez, D.P. Parekh, C. Ladd, D. Vashaee, M.D. Dickey and M.C. Öztürk, Flexible thermoelectric generator using bulk legs and liquid metal interconnects for wearable electronics, Appl Energy 202, $2017,736-745$.

[12] S. Qing, A. Rezania, L.A. Rosendahl and X. Gou, Design of flexible thermoelectric generator as human body sensor, Mater Today Proc 5, 2018, $10338-10346$.

[13] R. Amatya and R.J. Ram, Solar thermoelectric generator for micropower applications, J Electron Mater 39, 2010, 1735-1740.

[14] D. Madan, Z. Wang, P.K. Wright and J.W. Evans, Printed flexible thermoelectric generators for use on low levels of waste heat, Appl Energy 156, $2015,587-592$.

[15] P. Pichanusakorn and P. Bandaru, Nanostructured thermoelectrics, Mater Sci Eng R Rep 67, 2010, 19-63.

[16] W. He, G. Zhang, X. Zhang, J. Ji, G. Li and X. Zhao, Recent development and application of thermoelectric generator and cooler, Appl Energy 143, $2015,1-25$.

[17] S.B. Riffat and X. Ma, Thermoelectrics: a review of present and potential applications, Appl Therm Eng 23, 2003, 913-935.

[18] G. Li, S. Shittu, T.M.O. Diallo, M. Yu, X. Zhao and J. Ji, A review of solar photovoltaic-thermoelectric hybrid system for electricity generation, Energy 158, 2018, 41-58. 
[19] D. Champier, Thermoelectric generators: a review of applications, Energy Convers Manage 140, 2017, 167-181.

[20] J. Xiao, T. Yang, P. Li, P. Zhai and Q. Zhang, Thermal design and management for performance optimization of solar thermoelectric generator, Appl Energy 93, 2012, 33-38.

[21] G.J. Snyder, Application of the compatibility factor to the design of segmented and cascaded thermoelectric generators, Appl Phys Lett 84, 2004, 2436-2438.

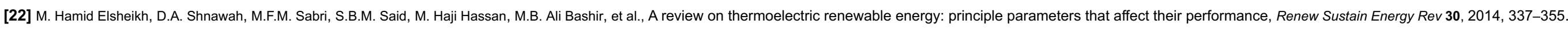

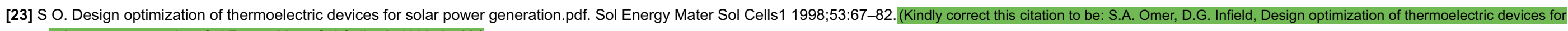
solar power generation, Sol Energy Mater Sol Cells 53, 1998, 67-82.)

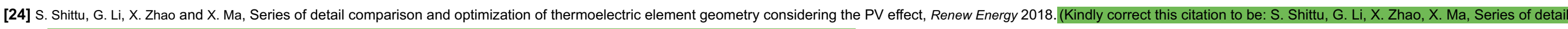
comparison and optimization of thermoelectric element geometry considering the PV effect, Renew Energy 130, 2019, 930-42.)

[25] G. Li, X. Zhao, Y. Jin, X. Chen, J. Ji and S. Shittu, Performance Analysis and Discussion on the Thermoelectric Element Footprint for PV-TE Maximum Power Generation, J Electron Mater 47, 2018, 5344-5351.

[26] G. Li, X. Zhao and J. Ji, Conceptual development of a novel photovoltaic-thermoelectric system and preliminary economic analysis, Energy Convers Manage 126, 2016, 935-943.

[27] G. Li, K. Zhou, Z. Song, X. Zhao and J. Ji, Inconsistent phenomenon of thermoelectric load resistance for photovoltaic-thermoelectric module, Energy Convers Manage 161, 2018, 155-161.

[28] G. Li, X. Chen and Y. Jin, Analysis of the primary constraint conditions of an efficient photovoltaic-thermoelectric hybrid system, Energies 10, 2017,1 1-12.

[29] G. Li, G. Zhang, W. He, J. Ji, S. Lv, X. Chen, et al., Performance analysis on a solar concentrating thermoelectric generator using the micro-channel heat pipe array, Energy Convers Manage 112, 2016, 191-198.

[30] W. He, Y. Su, Y.Q. Wang, S.B. Riffat and J. Ji, A study on incorporation of thermoelectric modules with evacuated-tube heat-pipe solar collectors, Renew Energy 37, 2012, 142-149.

[31] G. Li, W. Feng, Y. Jin, X. Chen and J. Ji, Discussion on the solar concentrating thermoelectric generation using micro-channel heat pipe array, Heat Mass Transf 53, 2017, 3249-3256.

[32] G. Li, J. Ji, G. Zhang, W. He, X. Chen and H. Chen, Performance analysis on a novel micro-channel heat pipe evacuated tube solar collector-incorporated thermoelectric generation, Int J Energy Res 40, 2016, 2117-2127.

[33] C. Hadjistassou, E. Kyriakides and J. Georgiou, Designing high efficiency segmented thermoelectric generators, Energy Convers Manage 66, 2013, 165-172.

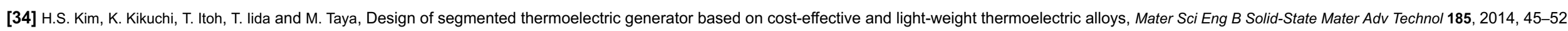

[35] G. Zhang, L. Fan, Z. Niu, K. Jiao, H. Diao, Q. Du, et al., A comprehensive design method for segmented thermoelectric generator, Energy Convers Manage 106, 2015, 510-519.

[36] H. Ali, B.S. Yilbas and F.A. Al-Sulaiman, Segmented thermoelectric generator: influence of pin shape configuration on the device performance, Energy 111, 2016, 439-452.

[37] H. Ali, B.S. Yilbas and A. Al-Sharafi, Innovative design of a thermoelectric generator with extended and segmented pin configurations, Appl Energy 187, 2017, 367-379.

[38] H. Ali and B.S. Yilbas, Innovative design of a thermoelectric generator of extended legs with tapering and segmented pin configuration: thermal performance analysis, Appl Therm Eng 123, $2017,74-91$.

[39] H.-B. Liu, J.-H. Meng, X.-D. Wang and W.-H. Chen, A new design of solar thermoelectric generator with combination of segmented materials and asymmetrical legs, Energy Convers Manage 175, 2018, 11-20.

[40] Y. Ge, Z. Liu, H. Sun and W. Liu, Optimal design of a segmented thermoelectric generator based on three-dimensional numerical simulation and multi-objective genetic algorithm, Energy 147, 2018, 1060-1069.

[41] Z. Ouyang and D. Li, Design of segmented high-performance thermoelectric generators with cost in consideration, Appl Energy 221, $2018,112-121$.

[42] G. Min and D.M. Rowe, Ring-structured thermoelectric module, Semicond Sci Technol 22, 2007, 880-883.

[43] A. Bauknecht, T. Steinert, C. Spengler and G. Suck, Analysis of annular thermoelectric couples with nonuniform temperature distribution by means of 3-D multiphysics simulation, J Electron Mater 42, 2013, 1641-1646.

[44] Z.G. Shen, S.Y. Wu and L. Xiao, Theoretical analysis on the performance of annular thermoelectric couple, Energy Convers Manage 89, $2015,244-250$.

[45] S.C. Kaushik and S. Manikandan, The influence of Thomson effect in the energy and exergy efficiency of an annular thermoelectric generator, Energy Convers Manage 103, 2015, 200-207. 
[46] S. Manikandan and S.C. Kaushik, Energy and exergy analysis of solar heat pipe based annular thermoelectric generator system, Sol Energy 135, $2016,569-577$.

[47] Z.-G. Shen, X. Liu, S. Chen, S.-Y. Wu, L. Xiao and Z.-X. Chen, Theoretical analysis on a segmented annular thermoelectric generator, Energy 157, $2018,297-313$.

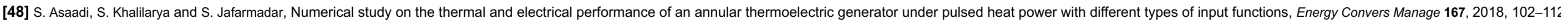

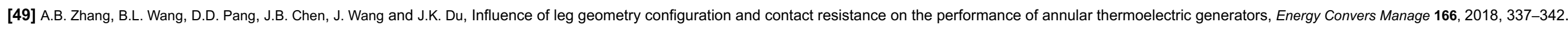

[50] A.B. Zhang, B.L. Wang, D.D. Pang, L.W. He, J. Lou, J. Wang, et al., Effects of interface layers on the performance of annular thermoelectric generators, Energy 147, $2018,612-620$.

[51] S. Fan and Y. Gao, Numerical simulation on thermoelectric and mechanical performance of annular thermoelectric generator, Energy 150, 2018, 38-48.

[52] B.S. Yilbas, S.S. Akhtar and A.Z. Sahin, Thermal and stress analyses in thermoelectric generator with tapered and rectangular pin configurations, Energy 114, 2016, 52-63.

[53] T. Clin, S. Turenne, D. Vasilevskiy and R.A. Masut, Numerical simulation of the thermomechanical behavior of extruded bismuth telluride alloy module, J Electron Mater 38, 2009 , 994-1001.

[54] Y. Mu, G. Chen, R. Yu, G. Li, P. Zhai and P. Li, Effect of geometric dimensions on thermoelectric and mechanical performance for Mg2Si-based thermoelectric unicouple, Mater Sci Semicond Process 17, 2014, 21-26.

[55] L. Bakhtiaryfard and Y.S. Chen, Design and analysis of a thermoelectric module to improve the operational life, Adv Mech Eng 7, $2015,1-22$.

[56] S. Turenne, T. Clin, D. Vasilevskiy and R.A. Masut, Finite element thermomechanical modeling of large area thermoelectric generators based on bismuth telluride alloys, J Electron Mater 39, 2010, 1926-1933.

[57] J.-L. Gao, Q.-G. Du, X.-D. Zhang and X.-Q. Jiang, Thermal stress analysis and structure parameter selection for a Bi2Te3-based thermoelectric module, J Electron Mater 40, 2011, 884-888.

[58] A.S. Al-Merbati, B.S. Yilbas and A.Z. Sahin, Thermodynamics and thermal stress analysis of thermoelectric power generator: influence of pin geometry on device performance, Appl Therm Eng 50, 2013, 683-692.

[59] Y. Wu, T. Ming, X. Li, T. Pan, K. Peng and X. Luo, Numerical simulations on the temperature gradient and thermal stress of a thermoelectric power generator, Energy Convers Manage 88, 2014, 915-927.

[60] U. Erturun, K. Erermis and K. Mossi, Effect of various leg geometries on thermo-mechanical and power generation performance of thermoelectric devices, Appl Therm Eng 73, 2014, 126-139.

[61] X. Jia and Y. Gao, Estimation of thermoelectric and mechanical performances of segmented thermoelectric generators under optimal operating conditions, Appl Therm Eng 73, 2014, 333-340.

[62] T. Ming, W. Yang, Y. Wu, Y. Xiang, X. Huang, J. Cheng, et al., Numerical analysis on the thermal behavior of a segmented thermoelectric generator, Int J Hydrogen Energy 42, 2017, 3521-3535.

[63] T. Ming, Y. Wu, C. Peng and Y. Tao, Thermal analysis on a segmented thermoelectric generator, Energy 80, 2015, 388-399.

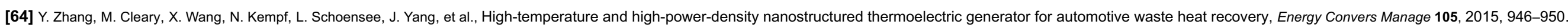

[65] Antonova EE, Looman DC. Finite elements for thermoelectric device analysis in ANSYS. ICT 2005. 24th linternational Conf. Thermoelectr., 2005, p. 200-3.

[66] N.Z.I.M. Sallehin, N.M. Yatim and S. Suhaimi, A review on fabrication methods for segmented thermoelectric structure, AIP Conf Proc 1972, $2018,30003$.

[67] G. Li, Q. An, W. Li, W.A. Goddard, P. Zhai, Q. Zhang, et al., Brittle failure mechanism in thermoelectric skutterudite CoSb3, Chem Mater 27, 2015, 6329-6336.

[68] X. Yang, P. Zhai, L. Liu and Q. Zhang, Thermodynamic and mechanical properties of crystalline CoSb(3): a molecular dynamics simulation study, J Appl Phys 109, 2011, 123517/1-123517/6.

[69] T. Caillat, A. Borshchevsky and J.P. Fleurial, Properties of single crystalline semiconducting CoSb3, J Appl Phys 80, 1996, 4442-4449.

\section{Highlights}

- A segmented annular thermoelectric generator (SATEG) is studied numerically.

- The thermoelectric and mechanical performance of SATEG is investigated. 


\section{Queries and Answers}

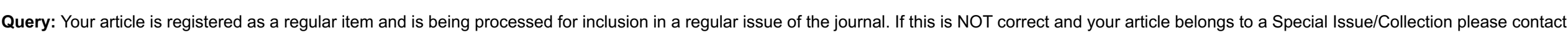
J.Shanmugam@elsevier.com immediately prior to returning your corrections.

Answer: Yes

Query: The author names have been tagged as given names and surnames (surnames are highlighted in teal color). Please confirm if they have been identified correctly. Answer: Yes

Query: Please note that equations were not sequentially cited in the text. Please check, and correct if necessary. Answer: This is correct as it is.

Query: Have we correctly interpreted the following funding source(s) and country names you cited in your article: EPSRC, United Kingdom? Innovate UK, United Kingdom? Answer: Yes 